(Fakul tas Kesehatan Universi tas Muhammadiyah Gresik)

Vol.1.No.1, Oktober 2020

\title{
Kesejahteraan Masyarakat Dengan Keluarga Berencana Bersama Masyarakat Desa Leran Kecamatan Manyar- Gresik Ade Ferry Sunaryati ${ }^{1)}$, Adelia Oktaviani' ${ }^{2}$, Nourma Yunita ${ }^{3)}$
}

\author{
1,2,3,Program Studi Kebidanan , Fakultas Kesehatan , Universitas Muhammadiyah Gresik \\ Jl. Proklamasi No.53 Gresik, Kecamatan Gresik, Kabupaten Gresik, Jawa Timur \\ e-mail correspondence : ${ }^{3)}$.nourta83@umg.ac.id
}

\begin{abstract}
Abstrak
Kegiatan komunitas di desa leran bertujuan menurunkan angka kelahiran yang naik, untuk mencapai kebijakan yang menyelamatkan ibu dan anak akibat melahirkan pada usia muda, jarak kelahiran terlalu dekat, melahirkan pada usia tua. Dalam Kegiatan ini juga mendukung upaya peningkatan pendapatan keluarga yang selanjutnya akan berdampak pada peningkatan kesejahteraan keluarga melalui pendekatan pemberdayaan. Pemberdayaan perempuan dilakukan dengan cara Peningkatan kesejahteraan melalui kesejahteraan KB (keluarga berencana), akan dilakukan dengan menggunakan pendekatan pada jejaring organisasi ibu-ibu PKK (Pemberdayaan Kesejahteraan Keluarga), Ibu Kader, dan Masyarakat yang telah terpilih saat dilakukannya SMD (survai mawas diri). Dalam melaksanakan peran, tugas dan fungsinya, Penyuluh KKBPK(Kependudukan Keluarga Berencana dan Pembangunan Keluarga) telah memiliki mekanisme kerja yang jalas, yaitu 10 Langkah. Diawali dengan langkah (1) Pendekatan Tokoh Formal; (2) Pendataan dan Pemetaan; (3) Pendekatan Tokoh Informal; (4) Pembentukan Kesepakatan; (5) Pemantapan Kesepakatan; (6) KIE (Komunikasi, Informasi, dan Edukasi.) kepada masyarakat; (7) Pembentukan Group Pelopor; (8) Pelayanan KB; (9) Pembinaan Peserta KB; dan (10) Evaluasi Hasil dari kegiatan SMD yakni sebanyak $150 \mathrm{KK}$ (kepala keluarga) dengan PUS (pasangan usia subur) yang ber KB berjumlah $42 \%$ dan PUS tanpa KB sebanyak 58\%. Dari hasil tersebut problem dari permasalahan yakni PUS Tanpa KB sebanyak $58 \%$ dan akan dilakukan pendekatan kepada anggota keluarga.
\end{abstract}

Kata kunci: PUS, Pengetahuan , KB, pengabdian masyarakat

\begin{abstract}
Community activities in Leran Village aim to reduce the rising birth rate, to achieve policies that save mothers and children due to childbirth at a young age, birth spacing is too close, giving birth at old age. This activity also supports efforts to increase family income which in turn will have an impact on improving family welfare through an empowerment approach. Empowerment of women is carried out by increasing welfare through family planning welfare, will be carried out by using an approach to the organization network of PKK mothers, Mother Cadres, and Communities who have been selected during the SMD . In carrying out their roles, duties and functions, the KKBPK Extension has a clear working mechanism, namely 10 Steps. Starting with the steps (1) Formal Figure Approach; (2) Data Collection and Mapping; (3) Informal Figure Approach; (4) Establishment of Agreement; (5) Consolidation of Agreement; (6) IEC To the public; (7) Establishment of Pioneer Group; (8) Family Planning Services; (9) Guidance for Family Planning Participants; and (10) Evaluation of the results of the SMD activities, namely as many as 150 families (heads of families) with PUS (couples of childbearing age) having family planning totaling $42 \%$ and PUS without family planning as many as 58\%. From these results, the problem of the problem is that of the PUS without family planning as much as $58 \%$ and an approach will be made to family members.
\end{abstract}

Key words: Fertile Age Couple, Knowledge, Contraception, Community Dedication 


\section{PENDAHULUAN}

Desa Leran dengan luas 1.367,79 Hektar, yang terdiri dari Pemukiman luasnya 47,07 Hektar, Tambak luasnya 1.188,80 Hektar, Sawah berluas 13,46 Hektar, Sungai / Bengawan luasnya yakni 86,68 Hektar, Jalan seluas 6,35 Hektar, Situs Makam Panjang dengan 2,43 Hektar dan Fasilitas Umum Lainnya seluas 23,00 Hektar. Jumlah penduduk desa Leran yakni sebanyak 5.364 jiwa, yang terdiri dari laki-laki 2.635 jiwa dan perempuan 2.729 jiwa, jumlah RT 16, jumlah RW 4, jumlah KK 1.320. Batas desa Leran di sebelah utara yakni desa Betoyo Kauman, Betoyo Guci, Banyuwangi, Manyar Sidomukti. Sebelah timur yakni Manyarejo, Peganden, Banjarsari. Sebelah selatan yakni desa Tebalo, Ambeng - Ambeng, Watangrejo. Dan Sebelah barat yaitu Petis Benem, Kemudi. Desa leran adalah desa yang yang memiliki wilayah berupa tambak paling besar. Hasil tambak Desa Leran adalah ikan bandeng, Udang, Mujair, Lele dengan hasil panen sebesar $500 \mathrm{~kg}-1$ kwintal per hektar

Desa Leran sangat memiliki banyak persediaan air bersih, sehingga masyarakat mudah untuk mendapatkan air dengan cara membeli air untuk kepentingan masak dan minum, sedangkan keperluan lain-lain diambil dari sumur atau PDAM. Terdapat 2 Sekolah Dasar di Desa Leran yaitu, MI Nurul Huda dan MI Leran. 1 Sekolah MTS yakni MTS Nurul Huda. Warga masyarakat memeriksakan kesehatan di Puskesmas yang berada di wilayah
Kecamatan Manyar yang berjarak 1 (satu) Km dari Desa Leran dan Puskesmas Pembantu berada di RT 05 RW 02 Desa Leran. Mata pencaharian Penduduk Desa leran mayoritas adalah karyawan swasta, yakni sebanyak 66,2\%. 7,74\% ibu-ibu di Desa leran adalah ibu rumah tangga yang tidak berpenghasilan. Dalam keluarga rata-rata memiliki anggota sebanyak 4 (empat) orang, dan rata penghasilan keluarga sudah sesuai dengan UMR Kabupaten Gresik. (Data Desa Leran Tahun 2019 )

Namun demikian apabila istri mampu memberikan tambahan pendapatan bagi keluarga maka diharapkan bisa meningkatkan kesejahteraan keluarga tersebut. Untuk meningkatkan pendapatan keluarga diperlukan upaya memberikan kesempatan yang setara kepada penduduk laki-laki dan perempuan dalam memenuhi kebutuhan keluarganya. Salah satu caranya adalah dengan lebih memberdayakan kaum perempuan agar ikut serta dan diperhitungkan dalam lapangan pekerjaan yang mampu menghasilkan keuntungan, sehingga pada akhirnya dapat membantu menopang pemenuhan kebutuhan hidup seluruh keluarga (Suyono, 2008).

Keluarga Berencana adalah Kunci utama penyelesaian masalah kesehatan reproduksi adalah program - program keluarga berencana melalui pilihan metode kontrasepsnya. KB merupakan landasan perempuan untuk mengatakan "NO" dalam rangka kematian dan morbiditas maternal. Program KB Nasional telah 
memiliki visi dan misi terbaru yang tertuang dalam RPJMN (Rencana Pembangunan Jangka Menengah ) tahun 2010 - 2014, yaitu dengan visi penduduk tumbuh seimbang 2015 dan misinya yakni mewujudkan pembangunan yang berwawasan kependudukan serta mewujudkan keluarga kecil bahagia sejahtera. Pembangunan kependudukan dan KB diharapkan dapat mempercepat pencapaian sasaran SDGs (Sustainable Development Goals) apalagi sebagian bersar indikator SDGs ini berkaitan dengan kesehatan, kependudukan, dan Keluarga Berencana. Untuk itu, perlu komitmen pemerintah daerah serta mitraa kerja disemua tingkatan dalam pembangunan kependudukan dan program KB didaerah. Sejak otonomi daerah, dudkungan pemerintah daerah kepada program KB menurun dan hal ini bia mempengaruhi derajat kesehatan ibu dan anak di Indonesia. Kebutuhan pelayanan KB yang tidak terpenuhi atau unmet need masih relatif tinggi, yaitu sebesar 8,5\%. (SDKI,2012 dan Harnani Yessi, 2015).

Keluarga berencana merupakan usaha untuk mengukur jumlah anak dan jarak kelahiran anak yang diinginkan. Maka dari itu, Pemerintah mencanangkan program atau cara untuk mencegah dan menunda kehamilan (Sulistyawati, 2013).

Tujuan program KB yaitu untuk menurunkan angka kelahiran yang bermakna, untuk mencapai tujuan tersebut maka diadakan kebijakaan yang dikategorikan dalam tiga fase (menjarangkan, menunda, dan menghentikan) maksud dari kebijakaan tersebut yaitu untuk menyelamatkan ibu dan anak akibat melahirkan pada usia muda, jarak kelahiran yang terlalu dekat dan melahirkan pada usia tua (Hartanto, 2012).

Ruang lingkup program KB secara umum adalah sebagai berikut : Keluarga berencana, Kesehatan reproduksi remaja, Ketahanan dan pemberdayaan keluarga, Penguatan pelembagaan keluarga kecil berkualitas, Keserasian kebijakan kependudukan, Pengelolaan Sumber Daya Manusia (SDM) dan Penyelenggaraan pimpinan kenegaraan dan kepemerintahan. (Sulistyawati, 2013).

Peningkatan kesejahteraan melalui kesejahteraan keluarga mengenai $\mathrm{KB}$, akan dilakukan dengan menggunakan pendekatan pada jejaring organisasi ibu-ibu PKK (Pemberdayaan Kesejahteraan Keluarga) dan Masyarakat yang telah terpilih saat dilakukannya SMD. Dimana selain jejaring organisasi PKK terorganisir secara baik juga kegiatannya sudah melembaga dan menjadi bagian dari kehidupan masyarakat Desa leran. Aktivitas kegiatan ibuibu PKK di Desa leran pada umumnya lebih banyak terkonsentrasi pada tingkat Rukun Tetangga (RT), Dusun atau Rukun Warga (RW). Salah satu sumber kesuksesan Program KKBPK adalah dengan adanya Penyuluh KB, Petugas Lapangan KB dan para Tenaga Penggerak Desa/Kelurahan. Penyuluh KKBPK memiliki peran sebagai penggerak yang handal untuk 
masyarakat agar dapat dukungan pengelolaan dan pelaksanaan Program KKBPK. Dalam melaksanakan peran, tugas dan fungsinya, Penyuluh KKBPK telah memiliki mekanisme kerja yang jalas, yaitu 10 Langkah. Diawali dengan langkah (1) Pendekatan Tokoh Formal; (2) Pendataan dan Pemetaan; (3) Pendekatan Tokoh Informal; (4) Pembentukan Kesepakatan; (5) Pemantapan Kesepakatan; (6) KIE kepada masyarakat; (7) Pembentukan Group Pelopor; (8) Pelayanan KB; (9) Pembinaan Peserta KB; dan (10) Evaluasi, Pencatatan dan Pelaporan. Langkah Kerja tersebut menjadikan kunci keberhasilan para Penyuluh KKBPK untuk berkontribusi terhadap pembangunan di desa/kelurahan serta pembangunan nasional secara umumnya (Hartanto, 2012).

\section{METODE}

\subsection{Rancangan Kegiatan}

Kegiatan Survei ini dikembangkan dengan pendekatan ilmiah melalui proses Survey Mawas Diri. Rangkaian dari pendekatan ilmiah tersebut adalah mengidentifikasi permasalahan, menentukan tujuan dan manfaat dan merancang prosedur pengabdian masyarakat, melakukan analisis terhadap data dan informasi, serta menjelaskan data dan menarik kesimpulan.

Dengan Kegiatan SMD tersebut maka bisa dapat menilai dan menganalisa masalah yang terjadi seperti banyaknya warga masyarakat desa Leran yang belum mengerti tentang $\mathrm{KB}$ dan masih ada yang belum ber KB.

2.2. Lokasi dan Kegiatan Survei Mawas Diri dan kegiatan penyuluhan $\mathrm{KB}$

Lokasi SMD didesa Leran yakni dengan pemilihan beberapa rumah tiap RT berjumlah 10 Kartu Keluarga dalam 15 RT. Menghasilkan 150 KK selama 3 hari. Kegiatan SMD ini dilakukan atas dasar pemilihan dari Dinas Kesehatan untuk mengkaji kesehatan yang ada di desa Leran. Bersama Kader Desa Leran atas izin dari Kepala Desa, Puskesmas Leran dan Bidan Desa Leran kita dapat melakukan Survei agar kita dapat mengangkat masalah yang terjadi di desa Leran.

Adapun kegiatan penyuluhan KB yakni bersama dengan para ibu PKK dan PUS tanpa KB di Balai desa Leran pada saat kegiatan PKK

\subsection{Bahan dan Alat}

a. Bahan dan Alat yang digunakan untuk SMD yakni Kertas SMD dari Puskesmas Leran, Bolpoint, Pensil, Senter, Abate, Sticker Abate.

b. Alat yang digunakan untuk penyuluhan yakni berupa Leaflet mengenai pengertian $\mathrm{KB}$, Macam - macam $\mathrm{KB}$, Komplikasi dan efek samping dari KB.

c. Media yang digunakan untuk penyuluhan seperti Laptop, LCD dan PPT serta Lembar balik KB. 
d. Data kegiatan SMD dan di kelompokkan untuk melakukan tindak lanjut ini diperoleh saat melakukan SMD dan akan dilakukan penyuluhan bagi keluarga yang telah masuk kriteria PUS tanpa KB bersama kader, bidan desa dan Ibu PKK.

\subsection{Metode Pelaksanaan Kegiatan}

Metode kegiatan yang dilakukan untuk mendapatkan hasil yakni berawal dari kunjungan rumah hari rabu - Jumat tanggal 08 - 10 Januari 2020, melakukan SMD dengan pengisian kertas SMD dan penilaian selintas keadaan rumah.

Pengumpulan data setelah SMD dan akan dilakukan tindakan penyuluhan pada hari senin tgl 20 Januari 2020. Adapun langkah-langkah yang digunakan dalam menyelesaikan persoalan Masyarakat tersebut yakni : Kepada para anggota akan didampingi oleh kader dan bidan desa untuk melakukan pemecahan masalah .

\section{HASIL DAN PEMBAHASAN}

Hasil dari kegiatan SMD yakni sebanyak $150 \mathrm{KK}$ dengan PUS yang ber KB berjumlah $42 \%$ dan PUS tanpa KB sebanyak 58\%. PUS yang menggunakan KB Suntik $1 / 3$ bulan sebanyak $25 \%$, KB pil $10 \%$, Implant $1 \%$, IUD 2\%, KB alamiah 3\%, MOW / MOP 15\%. Dari hasil tersebut problem dari permasalahan yakni PUS Tanpa KB sebanyak 58\% dan akan dilakukan pendekatan kepada anggota keluarga.

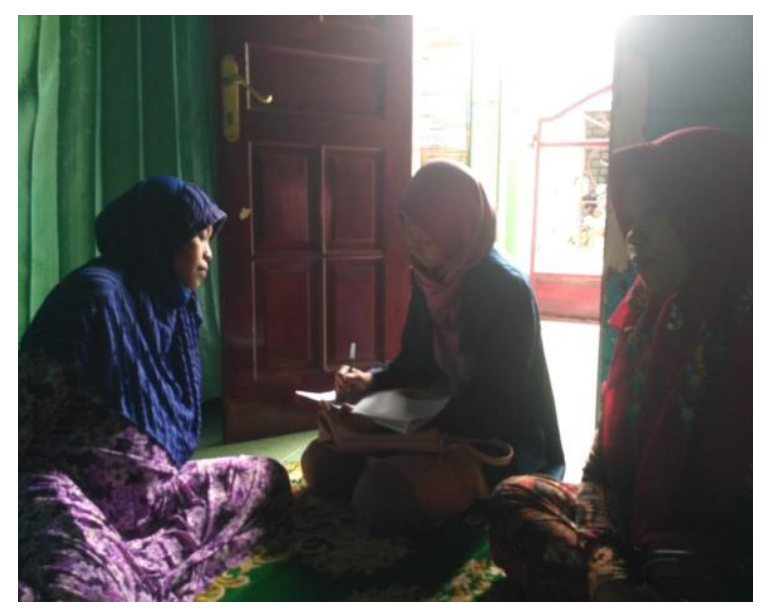

Gambar 1. Kegiatan SMD

Dilakukannya kegiatan penyuluhan bersama ibu PKK dan PUS tanpa KB pada tanggal 20 Januari 2020 untuk mensejahterakan warga Leran dengan mengurangi Angka Resiko tinggi. Dengan pendekatan terapeutik bersama dengan bidan desa dan kader kepada sasaran maka akan terjadi proses kesadaran bagi sasaran untuk memahami mengenai KB lebih jelas dan akan Ber KB.

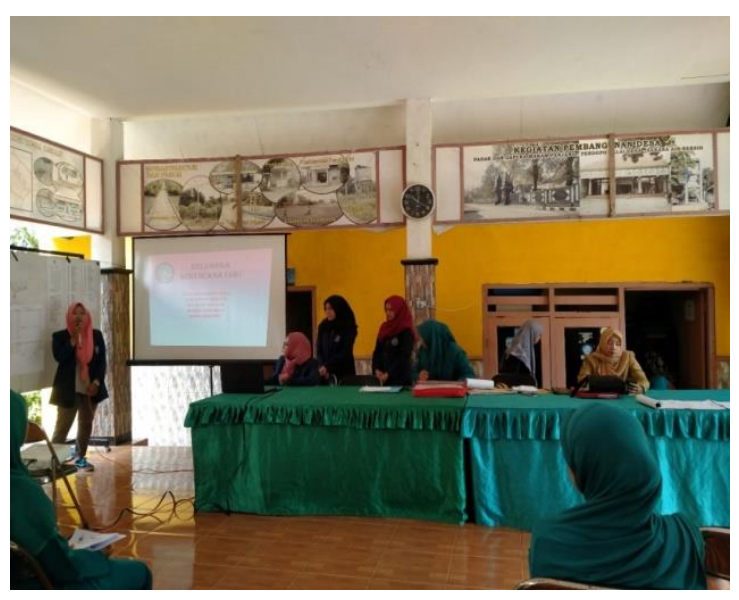

Gambar 2. Penyuluhan

Dengan adanya penyuluhan dan konseling KB pada tanggal 22 Januari 2020 maka ada data akseptor baru KB untuk PUS dengan pengontrolan bersama bidan desa dan 
kader untuk meningkatkan kesejahteraan keluarga menuju keluarga sehat.

\section{KESIMPULAN}

a. Sebagian besar warga desa Leran Tidak Ber KB dan hanya menggunkan KB alamiah tanpa adanya ilmu dan sumber dari tenaga kesehatan.

b. Ibu PKK dan PUS tanpa KB desa Leran belum pernah melakukan penyulihan $\mathrm{KB}$ dan konseling KB.

c. Kader Desa Leran dan Bidan Desa Leran belum melakukan pendekatan terapeutik dan pendataan kepada PUS tanpa KB.

d. Kegiatan Komunitas dengan melakukan kegiatan penyuluhan dan pendekatan kepada masyarakat terutama PUS tanpa KB sebagai acuan pokok untuk mengurangi angka resiko tinggi serta mengurangi jumlah kepadatan penduduk desa Leran.

\section{SARAN}

Kegiatan pengabdian seperti ini dapat dilakukan secara rutin baik di lokasi yang sama maupun di lokasi yang berbeda dengan sasaran masyarakat yang benar-benar membutuhkan pelayanan kesehatan terutama mengenai kesehatan pada remaja.
Data Hasil SMD tahun 2019

Harnani, Yessi, Marlina, \& H.Kursani, E. (2015). Teori kesehatan reproduksi .Yogyakarta: Deepublish.

Hartanto, H., 2012, Keluarga Berencana dan Kontrasepsi, Jakarta: PustakaSinar Harapan: 212-213.

Penyuluh KB Ujung Tombak Keberhasilan Program KKBPK 24 April 2018. https://www.bkkbn.go.id/detailpost/penyuluhkb-ujung-tombak-keberhasilan-programkkbpk. Diakses 06 Febeuari 2020

Sulistyawati, Ari.2013.Pelayanan Keluarga Berencana.Jakarta : SalembaMedika

Suyono, Slamet. (2008). Buku Ajar Ilmu Penyakit Dalam. Jakarta Pusat: Penerbitan Departemen Penyakit Dalam Fakultas Kedokteran Universitas Indonesia

\section{DAFTAR PUSTAKA}

Data Desa Leran Tahun 2019 